\title{
Ginseng, the 'Immunity Boost': The Effects of Panax ginseng on Immune System
}

\author{
Soowon Kang and Hyeyoung Min* \\ College of Pharmacy, Chung-Ang University, Seoul 156-756, Korea
}

\begin{abstract}
Thousands of literatures have described the diverse role of ginseng in physiological processes such as cancer, neurodegenerative disorders, insulin resistance, and hypertension. In particular, ginseng has been extensively reported to maintain homeostasis of the immune system and to enhance resistance to illness or microbial attacks through the regulation of immune system. Immune system comprises of different types of cells fulfilling their own specialized functions, and each type of the immune cells is differentially influenced and may be simultaneously controlled by ginseng treatment. This review summarizes the current knowledge on the effects of ginseng on immune system. We discuss how ginseng regulates each type of immune cells including macrophages, natural killer cells, dendritic cells, T cells, and B cells. We also describe how ginseng exhibits beneficial effects on controlling inflammatory diseases and microbial infections.
\end{abstract}

Keywords: Panax ginseng, Innate immunity, Acquired immunity, Immunomodulation, Cytokine

\section{INTRODUCTION}

Ginseng (the root of Panax ginseng Meyer, Family Araliaceae), one of the most well-known oriental medicinal herbs, has been widely used as an herbal remedy for various disorders [1]. Natural-dried ginseng is known as white ginseng, and red ginseng is prepared by steaming fresh ginseng root prior to drying on the purpose of enhancing efficacy, safety, and preservation [2].

Ginseng contains various pharmacological components including a series of tetracyclic triterpenoid saponins (ginsenosides), polyacetylenes, polyphenolic compounds, and acidic polysaccharides [3]. Ginsenosides can be classified into three groups based on the chemical structure of aglycones: the protopanaxadiol group (e.g., $\mathrm{Rb} 1, \mathrm{Rb} 2, \mathrm{Rb} 3, \mathrm{Rc}$, and $\mathrm{Rd}$ ); the protopanaxatriol group (e.g., Re, Rf, Rg1, and Rg2); and the oleanane group (e.g., Ro) (Fig. 1) [2,4]. Among these components, ginsenosides Rh2, Rs4, and Rg3 are found only in red ginseng

cc This is an Open Access article distributed under the terms of the Creative Commons Attribution Non-Commercial License (http://creativecommons.org/licenses/by-nc/3.0/) which permits unrestricted non-commercial use, distribution, and reproduction in any medium, provided the original work is properly cited. and are derived from the hydrolysis of saponins by heatprocessing [5]. Fermentation of red ginseng by intestinal microorganisms transforms saponins into readily absorbable forms such as compound K (20-O-D-glucopyranosyl-20[S]-protopanaxadiol) [6].

Ginseng has been well known as an immune modulator [7-10]. Roots (mostly), stems, leaves of ginseng, and their extracts have been used for maintaining immune homeostasis and enhancing resistance to illness or microbial attacks through effects on immune system. Immune system is composed of diverse types of cells with their own specialized functions, and each type of the immune cells differentially responds to ginseng treatment. This review summarizes the current knowledge on the effects of ginseng on immune system. Among the hundreds of literatures on immune responses, we only embraced the reports which used mice, rats, or humans as in vivo

Received 14 Jun. 2012, Revised 19 Jul. 2012, Accepted 19 Jul. 2012

*Corresponding author

E-mail: hymin@cau.ac.kr

Tel: +82-2-820-5618, Fax: +82-2-2-816-7338 
A

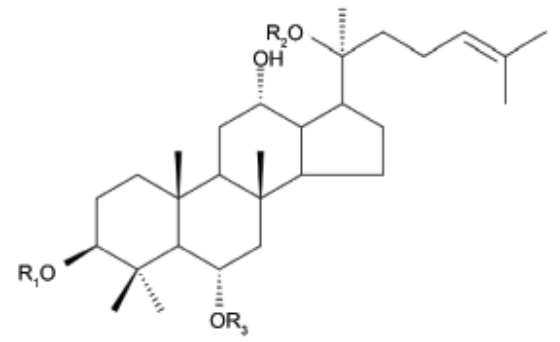

\begin{tabular}{|c|c|c|c|}
\hline Ginsenoside & R1 & R2 & R3 \\
\hline \multicolumn{4}{|c|}{ Protopanaxadiol-type } \\
\hline $\mathrm{Rb} 1$ & Glc $^{1}{ }^{2}$ Gle- & Glc ${ }^{1}{ }^{6} \mathrm{Glc}-$ & $\mathrm{H}$ \\
\hline $\mathrm{Rb} 2$ & $\mathrm{Gle}^{1}{ }^{2} \mathrm{Glc}-$ & $\operatorname{Ara}(p)^{1-6}{ }^{-6} \mathrm{Glc}-$ & $\mathrm{H}$ \\
\hline $\mathrm{Re}$ & Glc $^{1}-^{2}$ Glc- & $\operatorname{Ara}(f)^{1}-{ }^{6} \mathrm{Glc}-$ & $\mathrm{H}$ \\
\hline $\mathrm{Rd}$ & Gle ${ }^{1}{ }^{2} \mathrm{Glc}-$ & Glc- & $\mathrm{H}$ \\
\hline Rg3 & Gle $^{1-2}$ Gle- & H & $\mathrm{H}$ \\
\hline $\mathrm{Rh} 2$ & Glc- & $\mathrm{H}$ & $\mathrm{H}$ \\
\hline \multicolumn{4}{|c|}{ Protopanaxatriol-type } \\
\hline $\operatorname{Re}$ & H & Glc- & Rha'-2Glc- \\
\hline $\mathrm{Rf}$ & H & H & Glc1.2Gle- \\
\hline Rg1 & H & Gle- & Gle- \\
\hline $\mathrm{Rg} 2$ & H & $\mathrm{H}$ & Rha ${ }^{1}{ }^{2}$ Glc- \\
\hline Rh1 & H & H & Glc- \\
\hline
\end{tabular}

B

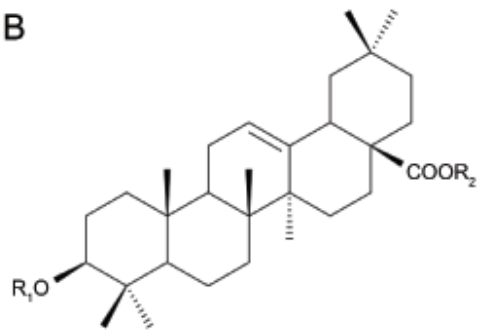

\begin{tabular}{ccc}
\hline & R1 & R2 \\
\hline Ginsenoside Ro & Glc ${ }^{1}{ }^{2}$ Glc- & Glc- \\
\hline
\end{tabular}

C

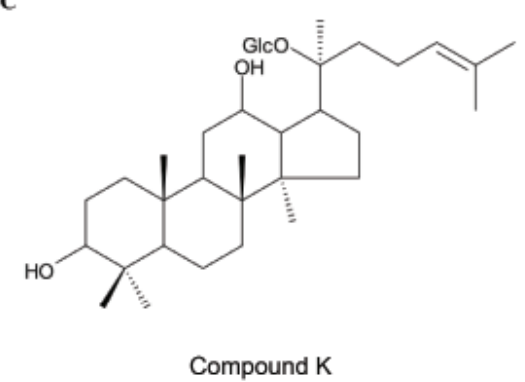

Fig. 1. Structures of saponins from Panax ginseng. (A) Protopanaxadiol- and protopanaxatriol-type saponins, (B) ginsenoside Ro, and (C) compound K. Glc, $\beta$-D-glucose; $\operatorname{Ara}(p)$, arabinose (pyranose form); Ara(f), arabinose (furanose form); Rha, $\alpha$-L-rhamnose.

model organisms, murine or human-derived cell lines as in vitro experimental models, and $P$. ginseng as a source of ginseng.

\section{INNATE IMMUNITY}

Innate immunity is the first barrier of defense against various infections by foreign organisms or substances (antigens), and is composed of four principal components. They comprise 1) physical/chemical barriers such as skin, mucous membranes, and the acidity of the stomach, 2) cellular components including phagocytes and natural killer cells, 3) blood proteins such as complements and inflammatory mediators, and 4) cytokines that regulating the cells of innate immune system $[11,12]$. These components of innate immunity recognize foreign microbes, initiate rapid primary immune responses, and prevent or eliminate infection of the host [13]. In addition to defensive function, innate immune system also generates a signal alarming the presence of infection, and thus stimulating a subsequent adaptive immune response [12]. Although an innate immunity comprises a variety of components mediating diverse functions, we only assess the effects of ginseng on cellular component in this review.

\section{Macrophages}

The mononuclear phagocytes are composed of monocytes circulating in the blood and macrophages in the tissues [14]. Macrophages exhibit different morphologic forms in different tissues, and they include microglia of the central nervous system, Kupffer cells in the liver, alveolar macrophages in the lung, and osteoclasts in bone [14]. Macrophages are principal components of innate defense against infections, and also play important roles in adaptive immune responses [12]. When activated by various stimuli, macrophages enhance phagocytic activity, increase the ability to kill ingested microbes, and produce many cytokines and inflammatory mediators such as nitric oxide and $\mathrm{H}_{2} \mathrm{O}_{2}$ [15]. They also express high levels of class II major histocompatibility complex (MHC) molecules to present antigens to helper T cells, and thereby connect the innate and adaptive immune systems [12].

Through numerous experiments, it was confirmed that ginseng extract enhanced phagocytic activity of macrophages [16]. Macrophages treated with ginseng polysaccharides stimulated the phagocytosis of zymosan, a preparation of cell wall from Saccharomyces cerevisiae, and peritoneal macrophages also showed an increase in 
phagocytosis following treatment with red ginseng acidic polysaccharides (RGAPs, ginsan) [16,17]. In a clinical trial with 20 healthy adults, oral administration of ginseng extract improved phagocytic activity [8].

In addition to the effects on phagocytosis, ginseng can stimulate the generation of inflammatory mediators such as nitric oxide (NO), a reactive nitrogen intermediate, through up-regulation of inducible nitric oxide synthase (iNOS) [18]. Macrophages produce NO in order to destroy phagocytized microbes, and ginseng aqueous extract and ginsan have shown to up-regulate NO production in activated RAW 264.7 cells and primary peritoneal macrophages, respectively $[16,18,19]$. In addition, treatment of macrophages with a combination of RGAPs and IFN- $\gamma$ has shown to potentiate the activation of macrophages, and NO production is greatly improved [18].

Upon activation by microbial products such as lipopolysaccharide (LPS) and IFN- $\gamma$ derived from natural killer (NK) cells, macrophages secrete IL- $1 \beta$ and TNF- $\alpha$ to induce inflammatory reactions, and IL-12 to stimulate NK cells and T cells to produce IFN- $\gamma[17,18]$. Isolated polysaccharides from $P$. ginseng augmented the secretion of IL-1 $\beta$ and TNF- $\alpha$ from peritoneal macrophages in vitro [17]. Treatment of macrophages with RGAPs and IFN $-\gamma$ significantly increased the production of IL- $1 \beta$ and TNF- $\alpha$ as well as NO as previously described [18]. IL12 release was also boosted up by treatment of murine J774A.1 macrophage cells with ginseng extract and its isolated components [20].

\section{Dendritic cells}

Dendritic cells (DC) play important roles in innate immune responses to infections and in linking innate and adaptive immune responses [21]. DCs recognize antigens at the first sites of defense, migrate into lymphoid organs, and present antigenic molecules to lymphocytes to initiate lymphocytes activation [21]. In addition, activated DCs release cytokines such as IL-12, IL-4, IFN- $\gamma$, and TNF- $\alpha$ to stimulate adaptive as well as innate immune responses [22].

In general, ginseng exhibits immunostimulatory effects on DCs [23,24]. Takei et al. [24] have reported that M1 and M4, end products of steroidal ginseng saponins metabolized in digestive tracts were able to drive the maturation of DC from human monocytes manifested by the increased expression of DC maturation markers such as MHC class II, CD80, CD83, and CD86. These surface molecules are associated with antigen-presenting capabilities of DCs implying that the increased expression of MHC class II and co-stimulatory molecules may enhance the differentiation and proliferation of lymphocytes. In fact, M4-primed mature DCs displayed enhanced T cells stimulatory capacity as measured by $\mathrm{T}$ cell proliferation, and the production of IFN- $\gamma$ and ${ }^{51} \mathrm{Cr}$ release on M4primed mature DCs were more augmented than those of control DCs. Similarly, ginsan also markedly increased the production of IL- 1 and TNF- $\alpha$ as well as the expression of maturation markers such as MHC class II and CD86 on DCs [23]. Subsequent experiment demonstrated that ginsan-treated DCs improved the proliferation of allogeneic $\mathrm{T}$ cells, corroborating the constructive role of ginseng on DC function.

However, some ginseng saponins have inhibitory effect on immune maturation of DCs. According to $\mathrm{Su}$ et al. [25], treatment of DCs with total saponins of $P$. ginseng followed by oxidized-low density lipoprotein diminished the secretion of cytokines such as IL-12 and TNF- $\alpha$, and the expression of maturation markers including CD40, CD86, CD1a, and HLA-DR. In other experiments using steamed ginseng-leaves and flowers, ginsenosides Rg6 and F4 exhibited inhibitory effects on bone marrowderived dendritic cells and decrease in the production of IL-12 p40, a subunit component of IL-12 upon LPS stimulation [26]. Although it remains unclear why ginseng showed such opposite effects, researchers suspect that ginseng may cause pro-maturation or anti-maturation of DCs and stimulate different signaling pathways [25].

\section{Natural killer cells}

NK cells are a type of cytotoxic lymphocytes of innate immune system that are involved in the first line of defense against newly arising malignant cells and infected cells [27]. Distinguished from cytotoxic T lymphocytes, they can recognize target cells in the absence of antibodies and MHC, and do not require activation to kill target cells thereby enabling a fast immune response [27]. In addition to killing target cells non-specifically, NK cells release pro-inflammatory cytokines such as IFN- $\gamma$ which activates macrophages to destroy phagocytized microbes [27].

Many literatures have reported that total ginseng extract enhances NK cell functions. Oral administration of aqueous extract of $P$. ginseng increased natural killing activity in mice [7], and ginsenoside Rg1-treated mice also showed an enhanced natural killing activity of the splenocytes [28]. Interestingly, the stimulatory effects of ginseng on NK cells were observed regardless of disease condition of the host. Therefore, the functions of NK cells stimulated by ginseng were comparable between immunosuppressed mice and immunocompetent mice 
[29]. The trial using blood sample of human patients who had chronic fatigue syndrome and acquired immunodeficiency syndrome (AIDS) showed functional enhancement of NK cells isolated from peripheral blood mononuclear cells [30]. In vivo test conducted by Scaglione et al. [8] also demonstrated that NK cell function in individuals taking ginseng was promoted compared to placebo group. Collectively, these results suggest that ginseng may improve NK cell activity irrespective of host immune conditions.

\section{ACQUIRED IMMUNITY}

Acquired (or adaptive) immunity is an antigen-specific immune response which occurs in response to the stimulation by specific antigens [31]. The major players of acquired immunity are lymphocytes such as $\mathrm{T}$ cells and $\mathrm{B}$ cells and their secreted antibodies. B lymphocytes play a role in the humoral immune response, whereas $\mathrm{T}$ lymphocytes are primarily involved in cell-mediated immune response [31]. The key feature of the adaptive immune response is its specificity and the ability to generate and maintain immunological memory [32]. Upon antigenic stimulation, antigen-specific lymphocytes proliferate and differentiate into effector cells whose function is to eliminate the antigen, and into memory cells which possess an enhanced response to subsequent encounters with the same antigen $[31,32]$.

\section{Humoral immune response}

The humoral immune response is an immunity mediated by antibodies [33]. In this response, the immune system triggers specific B cells (mostly, plasma cells) to proliferate and secrete large amounts of specific antibodies which then fight invading microorganisms or pathogenic antigens [33]. Antibodies can bind to the antigens such as toxin and virus, and keep them from contacting and harming normal cells of the body $[33,34]$. In addition, antigens coated with antibodies can be easily recognized, phagocytized, and destroyed by phagocytes or macrophages [35]. Antibodies are also able to stimulate complement system to form membrane attack complex on the membrane of invading microbes and kill them [36].

Although numerous studies describe the role of ginseng on antibody production, most of them evaluate its adjuvant potential on the secretion of specific antibodies. In general, ginseng extract successfully induced antigenspecific IgM, IgG, and IgA antibody responses when administered orally or intraperitoneally $[37,38]$. When mice were pre-treated with ginsan before oral-immunization of Salmonella for $2 \mathrm{wk}$, higher amounts of serum $\mathrm{IgG}_{1}$ and $\mathrm{IgG}_{2}$ as well as secretory IgA against Salmonella were produced [39]. In addition, subcutaneous injection of ginsenoside $\operatorname{Rg} 1$ developed a high level of specific antibody responses against Toxoplasma gondii and ginsenoside Re also significantly enhanced serum specific IgG, $\operatorname{IgG}_{1}, \operatorname{IgG}_{2 \mathrm{a}}$ and $\operatorname{IgG}_{2 b}$ responses to $\mathrm{H} 3 \mathrm{~N} 2$ influenza virus $[40,41]$. Collectively, ginseng extract or its purified components appear to elicit improved humoral responses against microbial invasion irrespective of administration methods or types of microbes, suggesting the critical roles of ginseng as an adjuvant in vaccines. More details on the adjuvant effects of ginseng are well described in 'GINSENG AS ADJUVANTS' section in this review.

While many studies have reported the enhanced humoral immune responses by ginseng treatment, ginseng also reduces antibody production in certain conditions. For example, long-term (30 consecutive days) oral administration of ginseng extract suppressed spleen cell function and considerably reduced $\operatorname{IgG}$ and $\operatorname{IgA}$ productions [38]. In addition, oral administration of ginseng extract also inhibited an increase in ovalbumin (OVA)specific $\mathrm{IgG}_{1}$ in the serum of OVA-sensitized mice without changing $\operatorname{IgG}_{2 \mathrm{a}}, \operatorname{Ig} \mathrm{A}$, and $\operatorname{IgE}$ levels [42].

\section{Cell-mediated immune response}

Cellular immune response is principally mediated by $\mathrm{T}$ cells and NK cells, and is most effective in destroying virus-infected cells, cells with intracellular bacteria, and cancer cells presenting tumor antigens $[43,44]$. It can also stimulate cells to release various cytokines in response to antigenic challenge and influence the function of numerous cells in the immune system [43]. Many reports have described that ginseng extract significantly enhances antibody-dependent cellular cytotoxicity and NK cell activity derived from human peripheral blood mononuclear cells $(\mathrm{PBMC})$ or mice $[7,29,30]$. In addition, ginsenoside $\mathrm{Rc}, \mathrm{Rd}, \mathrm{Rg} 1$, and ginsan all stimulated $\mathrm{T}$ cell proliferation as well as NK cell activity suggesting a critical immunomodulatory effect of ginseng on cellular immune responses [28,45-47].

In case of autoimmune diseases, immunosuppressive responses can exert beneficial effects on disease progression. Hwang et al. [46] has reported that ginsan promotes the generation of immunosuppressive regulatory $\mathrm{T}$ cells (Tregs) through the activation of transcription factor, FoxP3, indicating a favorable effect of ginsan on experimental autoimmune encephalomyelitis (EAE), a mouse model of multiple sclerosis (MS). 


\section{CYTOKINE RELEASE}

Cytokines are small signaling molecules that are secreted by a variety of cells mediating immune responses $[31,48]$. Cytokines are synthesized in response to microorganisms and other antigenic stimuli, and the binding of cytokines to their specific receptors triggers subsequent cascades of intracellular signaling and influences the development, differentiation, and function of immune cells [48]. Cytokines are often classified, based on their functional properties, into three categories, and they include modulators of innate immunity, modulators of adaptive immunity, and regulators of hematopoiesis [48]. However, this functional classification is not always distinct, and many cytokines play multiple roles in hematopoiesis and innate and adaptive immunity.

Many literatures have reported that ginseng regulates immune responses through the modulation of cytokine secretion. The affected cytokines are mostly proinflammatory cytokines via the activation or inhibition of Tolllike receptors (TLRs), but ginseng also changes cytokine production to control Th1/Th2 lineage differentiation. Detailed information on the role of ginseng on cytokine release is described below.

\section{Cytokines of innate immunity}

Different cytokines play critical roles in innate immunity against microbial invasion, and these mediators of innate immunity include TNFs, IL-1, IL-6, IL-10, IL12, type I interferons, and so on [49]. They are mainly secreted by macrophages and NK cells while some are produced by $\mathrm{T}$ cells, dendritic cells, and endothelial cells [49]. In order to detect microbial infection, the innate immune system uses pattern recognition receptors (PRRs), and TLRs are an important category of PRRs [50,51]. TLR detects the invasion of viruses, bacteria, fungi, and protozoa, and initiates signaling events which enable cells to control and clear infections.

Many literatures have shown that ginseng controls proinflammatory cytokine responses. TNF- $\alpha$, IL-1 $\beta$, IL-6, and IFN- $\gamma$ are produced by macrophages treated with ginseng radix extract (GRE) in vitro as well as in vivo [52]. Spleen cells cultured with ginsan induced an increase in IL-2, IFN- $\gamma$, IL-1 $\alpha$, and granulocyte-macrophage colony-stimulating factor production in vitro [53]. However, ginseng can also show opposite effects on cytokine production. The production of TNF- $\alpha$, IL-1 $\beta$, IL-6, IFN- $\gamma$, IL-12, and IL-18, was markedly down-regulated in ginsan-treated mice upon Staphylococcus aureus challenge, compared with those of control-infected mice
[54]. Ginseng saponin metabolite, compound K inhibited the expression of inducible nitric-oxide synthase and proinflammatory cytokines such as TNF- $\alpha$ and IL- $1 \beta$, and exerted anti-inflammatory effects in LPS-stimulated BV2 microglial cells and primary cultured microglia [55]. Similarly, Rg5, a major constituent of steamed ginseng reduced the expression of IL- $1 \beta$ and TNF- $\alpha$, as well as inflammatory enzymes, COX-2 and iNOS in LPS-stimulated alveolar macrophages [56]. In addition, the secretion of inflammatory cytokines such as IFN- $\gamma$, IL-1 $\beta$ and IL-17 were also reduced by ginsan treatment which is accompanied by a decrease in encephalitogenic response in EAE, an animal model of MS [46]. TNF- $\alpha$ production is significantly reduced by ginseng and ginsenoside $\mathrm{Rb} 1$, which leads to an anti-arthritic effect on collagen induced arthritis in mice [57].

The generation of proinflammatory cytokines is mainly through the activation of TLRs, and ginseng has been shown to modulate TLR activation by itself. While the production of TNF- $\alpha$ and IFN- $\gamma$ was induced by GRE in spleen cells and peritoneal macrophages from control mice, it was impaired in $\mathrm{C} 3 \mathrm{H} / \mathrm{HeJ}$ mice carrying a defective TLR-4 gene suggesting that GRE activates TLR4 signaling for cytokine release [58]. However, it seems that GRE does not contain LPS but have a non-LPS agent that can stimulate TLR-4 according to the endotoxin test with the threshold level of $1 \mathrm{ng} / \mathrm{mL}$. In contrast, some studies have demonstrated that ginseng downregulates TLRs and suppresses inflammatory response [54,59]. Ahn et al. [54] and Ahn et al. [59] reported the significant reduction of TLR-2 and its adaptor molecule MyD88 expression by ginsan treatment in vitro. In addition, expression of TLR-2, TLR-4, TLR-9, and MyD88 was considerably reduced in peritoneal macrophages treated with ginsan, and thereby mice were protected from $S$. aureus-induced sepsis [54].

These results indicate that ginseng modulates innate immunity through TLR expression, and ginseng or ginsan possesses an antiseptic activity by reducing proinflammatory cytokines via TLR signaling and prevents $S$. aureus-induced sepsis [54].

\section{Cytokines of acquired immunity}

The cytokines of acquired immunity are critical for the development and activation of effector cells [60]. The effector cells are further divided into Th1 cells which produce IL-2, IL-12, IFN- $\gamma$, and TNF- $\beta$, and Th 2 cells which secrete IL-4, IL-5, IL-10, and IL-13 [60]. The differences in the cytokines secreted by Th1 and Th2 cells determine their own differentiation and distinct biological functions 


\section{$[47,60,61]$.}

In addition to the effects on cytokines of innate immunity, ginseng also regulates the secretion of cytokines mediating adaptive immunity. Many literatures have reported that ginseng itself or various forms of purified ginsenoside control Th1 and Th2 immune response differentially [62-66]. The study by Larsen et al. [62] indicated that ginseng enhanced IL-2 production inducing a stronger Th1 response through the modulation of stimulated PBMC. Upon challenge with live Candida albicans, ginsenoside $\mathrm{Rg} 1$ helps the infected mice to resist candidiasis by developing Th1-dominant production of IFN- $\gamma$ and IL-2 [63]. Similarly, ginseng treatment in mice inoculated with Pseudomonas aeruginosa stimulated Th1 cytokine response resulting in a faster bacterial clearance from the lung and significantly milder lung pathology compared with control group [64]. In addition, ginsan induced the endogenous production of cytokines such as IL-1, IL-6, IFN- $\gamma$, and IL-12 which are required for hematopoietic recovery, and was able to enhance Th1 function while interfering with the Th2 response in irradiated mice [61]. However, according to the study by Lee et al. [47], $\mathrm{Rg} 1$ enhances Th2 lineage development from the naïve CD4+T cells both by increasing Th2 specific cytokine secretion such as IL-4 and by repressing Th1 specific cytokine production such as IFN- $\gamma$. Furthermore, when ginseng was used as an adjuvant for vaccination, it seemed to stimulate Th1 and Th2 cytokine responses equally. For example, when mice were immunized with vaccines containing ginsenoside $R b_{1}$ as adjuvant, augmented productions of IFN- $\gamma$, IL-2, IL-4, IL-10, and TNF- $\alpha$ were reported with no sign of polarization of the immune response [65]. Similarly, Rd also significantly promoted the production of the Th1 and Th2 cytokines in OVA-immunized mice [66]. Such disparities in controlling Th1/Th2 lineage differentiation may have arisen from differences in dosage, duration of exposure, route of administration, composition of the extract or the types of ginsenoside between the studies. Collectively, these results suggest that ginseng controls Th1/Th2 lineage differentiation by changing the balanced production of Th1 and Th 2 cytokines. Moreover, the Th1/Th2 fate decision process is not a unidirectional but bidirectional event which can change with different experimental conditions.

\section{EFFECTS OF GINSENG ON INFLAMMATORY DISEASE}

Inflammation is a physiological response to various stimuli such as invading pathogens, irritants, and tissue injury, and can be classified as acute or chronic [67]. In general, an acute inflammatory response has a rapid onset with short duration time, and is characterized by a rapid movement of plasma proteins and leukocytes to the injured tissues [67]. Although the acute response is a protective attempt to remove stimuli and to initiate the healing process, sustained inflammation may lead to a detrimental, pathologic consequences on host [68]. Such chronic inflammatory responses may result in significant tissue damages and develop to autoimmune diseases [69].

Ginseng has been shown to reduce the production of pro-inflammatory cytokines and thus, ameliorate the symptoms and the progression of inflammatory diseases $[54,70,71]$. In an ovalbumin-sensitized murine asthma model, ginseng effectively suppresses airway hyperresponsiveness by decreasing inflammatory cell infiltration, CD40 engagement of lymphocytes, eosinophil major basic protein production, and cytokine secretion [70]. This anti-asthmatic effect of ginseng was confirmed by Babayigit et al. [72] who have reported the improved histopathological changes of the lung in asthmatic mice with ginseng treatment. Additionally, Lim et al. [73] demonstrated that ginsan administration reduced airway hyperresponsiveness, remodeling and eosinophilia, which was equivalent to the effect of dexamethasone.

Ginseng can also protect host from bacterial septic responses through the suppression of robust acute inflammation. Sepsis is a dangerous and systemic disease caused by fatal and aberrant inflammatory response to infections [54]. As previously described in the 'Cytokines of innate immunity' section, ginsan and total polysaccharide have shown to suppress acute inflammation and protect host mice from sepsis-induced death upon bacterial challenge $[17,54,59]$. Interestingly, although the studies demonstrated the same anti-septic effects upon $S$. aureus challenge, the mechanisms behind showed discrepancy in cytokine production. For example, ginsan down-regulated the secretion of inflammatory cytokines such as IL$1 \beta$, IL-6, IFN- $\gamma$, IL-12, and IL-18, but total polysaccharide increased the level of IL-1 and IL- 6 . Collectively, the primary anti-septic protective effects given by ginsan or total polysaccharide seemed to be attributed to enhanced bacterial clearance through the augmented phagocytic activity of monocytes and macrophages rather than the reduced synthesis of sepsis-inducing inflammatory cytokines.

In addition, ginseng exerts beneficial effects on cerebral ischemia by modulating central nervous system inflammation [55,74]. Ginsenoside Rb1 depressed the activation of microglia and its conversion to phagocytic 
microglia as well as TNF- $\alpha$ and IL-6 production [74]. Compound $\mathrm{K}$ inhibited the expressions of inducible nitric-oxide synthase, proinflammatory cytokines such as TNF- $\alpha$ and IL-1 $\beta$, monocyte chemotactic protein-1, and matrix metalloproteinase-3 and -9 in LPS-stimulated BV2 microglial cells and primary cultured microglia [55]. These results propose the application of ginseng as a neuroprotective agent for prevention and/or treatment of neuroinflammatory diseases such as cerebral ischemia.

In the murine model of collagen-induced arthritis, red ginseng saponin extract including ginsenosides Rg3, Rk1 and Rg5, n-butanol extract, and ginsenoside Rb1 all showed anti-arthritic effects $[57,75,76]$. They presented reduced inflammatory cell infiltration, cytokine production, and cartilage destruction, and thereby ameliorated the clinical arthritis score significantly. Taken together, the results suggest that various forms of ginseng could be beneficial supplements or alternatives to the current anti-TNF- $\alpha$ therapeutics for rheumatoid arthritis or other inflammatory diseases characterized by TNF- $\alpha$ up-regulation.

Lastly, numerous literatures have described the effects of ginseng on contact and atopic dermatitis [77-82]. Korean red ginseng (KRG) extracts have been shown to suppress the production of TNF- $\alpha$ and IL- 8 in human keratinocytes [78]. Furthermore, in a mouse model of atopic dermatitis, topical application of ginseng extract or ginsenoside $\mathrm{Rb} 1$ significantly improved the atopic dermatitis-like skin lesion and scratching behavior as well as the decrease of serum IgE, IL-4, and IL-10 [5,79,81]. This anti-atopic dermatitis effect was also observed in mice when KRG was given orally [80], and further confirmed in the human study with 30 atopic patients. Lee and Son [82] reported that 16-week oral ingestion of KRG decreased serum IgE level and the severity of scoring of the atopic dermatitis index, suggesting a role of $\mathrm{KRG}$ as a functional food for atopic dermatitis.

\section{ANTI-MICROBIAL ACTIVITY OF GINSENG}

Plants are continuously in contact with different microorganisms such as viruses, bacteria and fungi. The interactions between plants and microbes may be beneficial for the plants, but many plant-associated microbes are pathogens which affect development, reproduction, and growth of the plants [83]. Therefore, plants produce antimicrobial compounds as a defense mechanism against microbial attacks, and these plant-derived compounds have been reported to prevent bacterial or viral infection also in humans. Especially, ginseng is one of the best- known medicinal herbs improving microbial clearance from the body $[8,84,85]$. Total ginseng extracts as well as single or multiple components derived from ginseng have shown anti-microbial activities, and clinical trials have also been performed to evaluate the anti-bacterial or anti-viral activities of ginseng.

\section{Anti-bacterial activity}

For successful establishment of bacterial infections, it is necessary to have adhesion to host cells, colonization of tissues, and in certain cases, cellular invasion followed by intracellular multiplication, dissemination to other tissues, or persistence [86]. In general, bacterial adhesion is mediated by certain interactions between adhesin from bacteria and carbohydrates on the surface of host cells. Studies have shown that ginseng polysaccharides could interact with microbes, interrupt microbial adhesion to host cells, and block the initiation of infectious disease $[87,88]$. For example, PG-F2 and PG-HMW, pectintype polysaccharides from $P$. ginseng, had anti-adhesive activity against various microbes such as Porphyromonas gingivalis, Actinobacillus actinomycetemcomitans, Propionibacterium acnes, and S. aureus [87]. These two polysaccharides did not directly affect microbial growth but decreased the percentages of attached microbe, suggesting that ginseng polysaccharides have potential roles in anti-adhesive activity. In addition, polyacetylenes isolated from $P$. ginseng hairy root culture exerts direct bactericidal effects [89]. Four different polyacetylene compounds were treated to various microorganisms such as Gram-positive bacteria (methicillin-resistant $S$. aureus and Bacillus subtilis) and Gram-negative bacteria (Escherichia coli and Serratia marcescens), and their minimum inhibitory concentrations were measured. The results show that polyacetylene compounds were effective against bacterial infections and the level of antibacterial activity was dependent on structural features of the polyacetylene.

Additionally, ginsan had bactericidal activity against S. aureus [54]. Although ginsan treatment had no direct effects on bacterial killing in vitro, pretreatment of mice with ginsan showed enhanced anti-Staphylococcal activity by decreasing the numbers of bacteria present in the spleens, kidney, and blood. The phagocytic activity against $S$. aureus was also enhanced considerably in ginsan-treated mice. In addition to bactericidal activity, ginseng polysaccharide and ginsan showed anti-septicaemic effects against $S$. aureus infection and protected mice from septic death during early acute inflammation as previously discussed [17,54]. 
Microorganisms have their own specific mode of action by which they survive or exert pathogenic effects in the host. Ginseng can inhibit those survival or pathogenic mechanisms and thereby exhibit anti-bacterial ability. For example, acidic saccharides from $P$. ginseng and red ginseng extract (RGE) have shown to possess the protective effects against Helicobacter pylori causing gastric inflammation, ulceration, and DNA damage $[88,90,91]$. Through the treatment of acidic saccharides from $P$. ginseng, H. pylori could not attach to gastric cells and initiate inflammatory responses [88,90,91]. Moreover, RGE was identified to significantly weaken both $H$. pyloriinduced DNA damage and gastric cell apoptosis by inactivating ERK1/2 signaling and attenuating caspase-3 activation and poly ADP ribose polymerase cleavage [91].

Furthermore, literatures have described the antiPseudomonal activity of ginseng. Ginseng treatment significantly decreased the lung pathology and enhanced bacterial clearance from the lung in a rat model of chronic $P$. aeruginosa lung infection mimicking cystic fibrosis $[64,84,85,92]$. During infectious process by $P$. aeruginosa, cell-to-cell communication mechanism called quorum sensing (QS) plays a critical role in the pathogenesis of the bacteria. The QS of $P$. aeruginosa uses Nacetylated homoserine lactone as a signal molecule and coordinates the formation of biofilms, swarming motility, exopolysaccharide production, and cell aggregation. Song et al. [93] have shown that hot water extracts from ginseng compromises the generation of $P$. aeruginosa QS. Although hot water ginseng extracts did not inhibit the growth of $P$. aeruginosa directly and enhanced the production of capsule-like polysaccharides and alginates, ginseng extracts suppressed the synthesis of virulence factors such as LasA protease, LasB elastase, and AHL molecules, and strongly inhibited QS system of $P$. aeruginosa [93].

\section{Anti-viral activity}

Influenza virus, commonly referred to as the flu, can be influenced by RGE [94-97]. After intranasal administration of ginseng extract with influenza virus A/PR8, significant increases in IgA as well as total $\operatorname{IgG}$ were observed in blood, lung, vaginal lavage, and fecal extract in mice [98]. The increase in total IgG was comparable to that observed in the aluminium hydroxide or cholera toxin-adjuvant group. In addition, all serum IgG subtypes such as $\operatorname{IgG}_{1}, \operatorname{IgG}_{2 \mathrm{a}}, \operatorname{IgG}_{2 \mathrm{~b}}$, and $\operatorname{IgG}_{3}$ antibodies were all augmented [98]. Simultaneously, virus neutralization activity, cytokine production, body weight changes, and survival rates were all improved by ginseng treatment indicating that ginseng extract well-executes immunoregulatory function as an adjuvant.

Avian influenza H9N2 is generally related to major mortality of human endothelial cells and causes serious inflammation and apoptosis on host cells [95,96]. H9N2 may induce the generation of reactive oxygen species (ROS), stimulate inflammatory response by producing IP-10 chemokine, and cause cellular apoptosis and DNA damages. Two ginsenosides have shown to possess different protective functions against H9N2 and mediate dual roles in infectious situations [95]. Ginsenoside protopanaxatriol reduced ROS stress and decreased IP10 expression stimulated by ROS, whereas ginsenoside Re reduced the influenza-induced DNA damage and cell death.

Infection of influenza A (H1N1) virus is also regulated by red ginseng extracts [97]. RGE treatment inhibited plaque formation occurred by influenza A virus in cellbased system, and oral administration of RGE improved body weight loss and decreased influenza A titer in mouse lung.

Human immunodeficiency virus type 1 (HIV-1) is a virus that causes AIDS, a condition in which the immune system fails due to the destruction of CD4+ helper T cells (mostly), macrophages, and dendritic cells $[99,100]$. Owing to the introduction of highly active anti-retroviral therapy (HAART) and the development of many anti-retroviral drugs, the rates of mortality and morbidity related to HIV-1 disease have reduced meaningfully [101]. However, anti-retroviral drug-resistant mutants are incessantly occurring and limit the availability of effective drugs. Interestingly, KRG has been shown to exert positive effects on HAART by maintaining CD4+ T cell counts and delaying the development of resistance mutations in HIV-1 patients treated with HAART [102]. Negative factor (Nef) is a virulence factor securing $\mathrm{T}$ cell activation and the establishment of a persistent state of infection early in the HIV life cycle. Nef proteins derived from the long-term non/slow progressors were found to be defective or far less capable of enhancing viral replication and infectivity [103]. Interestingly, KRG increases the frequency of gross deletion in the nef gene resulting in the delay in disease progression in HIV-1 patients [104-107]. Similarly, increased frequency of deletion in the HIV-1 5' LTR/gag was found in HIV-1 infected long-term survivors treated with $\mathrm{KRG}$, suggesting the association of gross deletion in HIV-1 5' LTR/gag regions with KRG intake [107-109]. Therefore, combinational treatment or pre-treatment of KRG with HAART is very valuable for the treatment of HIV infections. 
Ginseng also had inhibitory effects on the growth of other viruses such as rotavirus, murine norovirus (MNV), and feline calicivirus (FCV) [110,111]. Pre-treatment but not post-treatment of mice with RGE exhibited antiviral effects on MNV and FCV, surrogates for human norovirus. In addition, ginseng polysaccharide fractions showed anti-rotaviral activity with the inhibitory potency comparable to that of hesperidin, one of the most potent agent for rotaviral infection [111].

Although the eradication of viral infection mainly relies on the immune responses of the host, anti-viral properties of ginseng have been rarely assessed from an immunological perspective. Instead of examining the activities of cytotoxic T cells and NK cells and the production of interferon and neutralizing antibody, body weight loss, survival rate, virus titer, and genetic mutation of virulence factors have been employed to prove anti-viral activities of ginseng. Future studies should include the immunological methods described above to assess antiviral activity of ginseng more thoroughly.

\section{GINSENG AS ADJUVANTS}

Adjuvants play an important role in vaccine formulations by increasing the immunogenicity of co-administered antigens $[112,113]$. When appropriate adjuvants are administrated with a supplied antigen, they can enhance immunization effects while keeping the injected antigen to a minimum and protect their recipients from deadly infectious diseases. Adjuvants can act in various ways to increase antigen presentation and to stimulate the immune system [114]. For example, adjuvants may act as a depot for the antigen and present the antigen over a long period of time to maximize the immune responses. They can also induce mucosal immunity, regulate antibody avidity, specificity, or isotype, and stimulate cytotoxic T lymphocytes. Many substances have been developed as adjuvants [112]. Inorganic aluminium salts such as aluminium phosphate and aluminium hydroxide are one of the most common adjuvants in human vaccine. In addition, oil emulsions, polymers, carbohydrates, liposomes, LPSs and other bacterial toxins are also used to augment immune responses.

Ginseng extract has been applied as an immunologic adjuvant and ginsenosides are believed to be the key molecules that have adjuvanticity among the whole ginseng extract [115]. There are about 30 ginsenosides present in $P$. ginseng and their ability as an adjuvant is dependent on their characteristic structural features [116,117]. In general, ginseng has no immunogenicity by itself [118].
However, their combinations with antigens or other adjuvants can promote and enhance immune responses against immunized antigens.

Antibody production could be regulated by ginseng extract and specific ginsenoside. It has been reported that ginseng extract increases IgM and IgG antibody responses in immunized mice [7], and ginsenosides Rd, Re and Rg1 also augment specific-antibody responses $[41,66,118$ 121]. Similarly, a novel adjuvant of ginsenoside-based nanoparticles (ginsomes) containing ginsenosides $\mathrm{Rb} 2$, $\mathrm{Rc}, \mathrm{Rb} 1$, and Rd significantly increased the levels of specific $\mathrm{IgG}_{1}, \operatorname{IgG}_{2 \mathrm{a}}, \mathrm{IgG}_{2 \mathrm{~b}}$ and $\mathrm{IgG}_{3}$ in mice [119].

Recent studies of ginseng also emphasize the adjuvant effects of ginseng on the Th1 and Th2 immune responses as well as antibody responses. In addition to increase in lymphocyte proliferation, ginseng promotes the production of cytokines which stimulate both Th1 and Th2 immune responses. The productions of IFN- $\gamma$ and IL-5 were increased by administration of ginsenoside Re and Rg1 in mice [118,119,121]. Ginsenoside Rd and Re also improved the productions of Th1 and Th2 cytokines including IFN- $\gamma$, IL-2, IL-4, IL-10, IL-12, and TNF- $\alpha$ $[41,66,120]$, and consequently, up-regulated Th1 and Th2 responses leading to a balanced immunity.

For these reasons, ginseng has been suggested as a potent adjuvant for vaccine. For example, in the vaccine of $T$. gondii, ginseng was regarded as a promising vaccine adjuvant against toxoplasmosis by enhancing antibody response against $T$. gondii antigen [41]. In influenza virus vaccine, ginsenoside $R e$ is expected to improve the quality of vaccine that may activate mixed Th1/Th2 immune responses [118]. Overall, these results indicate that ginseng functions well as an immunologic adjuvant, and its combination with antigens would bring enhanced immune responses during immunization.

\section{CONCLUDING REMARKS}

Here we discussed the current knowledge on the effects of ginseng on immune system (Table 1). Although ample studies have examined the immunomodulatory properties of ginseng in vitro and in animals, most of them are limited to assess the phenotypic changes at the cellular level, and only a few studies have looked at the alterations by ginseng at the molecular level. For example, cytokine secretion, antibody production, surface marker expression, and cellular functions such as phagocytosis and cytotoxicity were common criteria to evaluate immunoregulatory properties, while molecular components involved in signaling pathway were rarely 
Table 1. Summary of the ginseng effects on immune system

\begin{tabular}{|c|c|c|}
\hline & Effects & References \\
\hline \multicolumn{3}{|l|}{ Innate immunity } \\
\hline \multirow[t]{4}{*}{ Macrophages } & Enhance phagocytosis & {$[8,16,17]$} \\
\hline & Stimulate the generation of nitric oxide & {$[16,18,19]$} \\
\hline & Induce inflammatory reactions by IL- $1 \beta$ and TNF- $\alpha$ & {$[17,18]$} \\
\hline & Stimulate NK cells and T cells by IL- 12 & {$[20]$} \\
\hline \multirow[t]{4}{*}{ DCs } & Increase DC maturation markers (MHC class II, CD80, CD83, CD86) & {$[23,24]$} \\
\hline & Increase the production of IL-1 and TNF- $\alpha$ & {$[23]$} \\
\hline & Reduce DC maturation markers (CD40, CD86, CD1a, HLA-DR) & {$[25]$} \\
\hline & Diminish the secretion of TNF- $\alpha$, IL-12 and IL-12 p40 & {$[25,26]$} \\
\hline NK cells & Improve natural killing activity & {$[7,8,28-30]$} \\
\hline \multicolumn{3}{|l|}{ Acquired immunity } \\
\hline \multirow[t]{2}{*}{ Humoral immunity } & Induce responses and production of $\operatorname{IgA}, \operatorname{IgM}, \operatorname{IgG}$ and $\operatorname{IgG}$ subunits & {$[37-41]$} \\
\hline & Inhibit the OVA-sensitized decrease in IgA level in the small intestine & {$[42]$} \\
\hline \multirow[t]{3}{*}{ Cell-mediated immunity } & Enhance antibody-dependent cellular cytotoxicity & {$[7,29,30]$} \\
\hline & Stimulate $\mathrm{T}$ cell proliferation & {$[28,45-47]$} \\
\hline & Promote the generation of immunosuppressive regulatory $\mathrm{T}$ cells (Tregs) & {$[46]$} \\
\hline \multicolumn{3}{|l|}{ Cytokine release } \\
\hline \multirow[t]{5}{*}{ Of innate immunity } & Produce TNF- $\alpha$, IL-1 $\beta$, IL- 6 , and IFN- $\gamma$ by macrophages & {$[52]$} \\
\hline & Increase IL-2, IFN- $\gamma$, IL-1 $\alpha$, and GM-CSF production & {$[53]$} \\
\hline & Decrease TNF- $\alpha$, IL-1 $\beta$, IL-6, IFN- $\gamma$, IL-12, and IL-1 18 by TLR reduction & {$[54]$} \\
\hline & Reduce nitric oxide synthesis and production of TNF- $\alpha$ and IL- $1 \beta$ & {$[55-57]$} \\
\hline & Inhibit secretion of IL- $1 \beta$, IL-17 and IFN- $\gamma$ & {$[46]$} \\
\hline \multirow[t]{4}{*}{ Of acquired immunity } & Enhance production of IFN- $\gamma$ and IL-2 & {$[62,63]$} \\
\hline & Increase generation of IL-1, IL-6, IFN- $\gamma$, and IL-12 & {$[61]$} \\
\hline & Increase Th2 cytokine (e.g., IL-4) and repress Th1 cytokine (e.g., IFN- $\gamma$ ) & {$[47]$} \\
\hline & Stimulate Th1 and Th2 cytokine equally (IFN- $\gamma$, IL-2, IL-4, IL-10, and TNF- $\alpha$ ) & {$[65,66]$} \\
\hline
\end{tabular}

Inflammatory disease regulation

Mitigate asthma symptoms suppressing airway hyperresponsiveness $\quad[70,72,73]$

Protect host from bacterial septic responses $\quad[17,54,59]$

Modulate CNS inflammation and improve cerebral ischemia [55,74]

Ameliorate arthritis by reducing inflammatory cell infiltration, cytokine production, and cartilage destruction $\quad[57,75,76]$

Alleviate atopic dermatitis by decreasing inflammatory cytokines [77-82]

Anti-microbial activity

Bacteria Interrupt microbial adhesion to host cells

Kill Gram positive and Gram nagative bacteria directly [ [89]

Inhibit survival or pathogenic mechanism of specific pathogen $\quad[88,90,91]$

Enhance bacterial clearance and decrease pathology $\quad[64,84,85,92]$

Interrupt quorum sensing system [93]

Increase antibody production and response with influenza virus A/PR8 infection

Increase antibody production and response with influenza virus A/PR8 infection

Inhibit proliferation of influenza virus A (H1N1) [97]
[10

HIV-1 Increase the frequency of gross deletion in the nef gene [104-107]

Increases the frequency of gross deletion in HIV-1 5' LTR/ gag regions [107-109]

Others Inhibit viral growth of rotavirus, MNV and FCV [110,111]

Adjuvant

NK, natural killer; DC, dendritic cells; MHC, major histocompatibility complex; OVA, ovalbumin; GM-CSF, granulocyte-macrophage colony-stimulating factor; CNS, central nervous system; ROS, reactive oxygen species; HIV-1, human immunodeficiency virus type 1; MNV, murine norovirus; FCV, feline calicivirus. 
investigated. In order to reveal the underlying molecular mechanisms for the immunomodulating effects of ginseng in more detail, further in-depth studies need to be provided.

As a well-known herbal immune stimulant, hundreds of studies have extensively reported the anti-cancer or chemopreventive effects of ginseng. The anti-cancer effects of ginseng are mainly through the improvements in cell-mediated immunity consisting of cytotoxic T cells and NK cells, while other mechanisms such as oxidative stress, apoptosis, and angiogenesis are also involved. A comprehensive review dealing with anti-cancer effects from the immunological point of view would be imperative in the near future.

\section{ACKNOWLEDGEMENTS}

This research was supported by the Public welfare \& Safety research program through the National Research Foundation of Korea funded by the Ministry of Education, Science and Technology (2010-0020842).

\section{REFERENCES}

1. Akerele O. WHO guideline for assessment of herbal medicines. Fitoterapia 1992;63:99-104.

2. Baek SH, Bae ON, Park JH. Recent methodology in ginseng analysis. J Ginseng Res 2012;36:119-134.

3. Kim MK, Lee JW, Lee KY, Yang DC. Microbial conversion of major ginsenoside $\mathrm{Rb} 1$ to pharmaceutically active minor ginsenoside Rd. J Microbiol 2005;43:456-462.

4. Cui J, Garle M, Eneroth P, Bjorkhem I. What do commercial ginseng preparations contain? Lancet 1994;344:134.

5. Sohn EH, Jang SA, Lee CH, Jang KH, Kang SC, Park HJ, Pyo SN. Effects of Korean red ginseng extract for the treatment of atopic dermatitis-like skin lesions in mice. J Ginseng Res 2011;35:479-486.

6. Bae EA, Park SY, Kim DH. Constitutive beta-glucosidases hydrolyzing ginsenoside $\mathrm{Rb} 1$ and $\mathrm{Rb} 2$ from human intestinal bacteria. Biol Pharm Bull 2000;23:1481-1485.

7. Jie YH, Cammisuli S, Baggiolini M. Immunomodulatory effects of Panax ginseng C.A. Meyer in the mouse. Agents Actions 1984;15:386-391.

8. Scaglione F, Ferrara F, Dugnani S, Falchi M, Santoro G, Fraschini F. Immunomodulatory effects of two extracts of Panax ginseng C.A. Meyer. Drugs Exp Clin Res 1990;16:537-542.

9. Choi KT. Botanical characteristics, pharmacological effects and medicinal components of Korean Panax ginseng C A Meyer. Acta Pharmacol Sin 2008;29:1109-1118.
10. Kitts D, Hu C. Efficacy and safety of ginseng. Public Health Nutr 2000;3:473-485.

11. Elias PM. The skin barrier as an innate immune element. Semin Immunopathol 2007;29:3-14.

12. Medzhitov R, Janeway CA Jr. Innate immunity: impact on the adaptive immune response. Curr Opin Immunol 1997;9:4-9.

13. Albiger B, Dahlberg S, Henriques-Normark B, Normark S. Role of the innate immune system in host defence against bacterial infections: focus on the Toll-like receptors. J Intern Med 2007;261:511-528.

14. Gordon S. The macrophage. Bioessays 1995;17:977-986.

15. Guzik TJ, Korbut R, Adamek-Guzik T. Nitric oxide and superoxide in inflammation and immune regulation. J Physiol Pharmacol 2003;54:469-487.

16. Shin JY, Song JY, Yun YS, Yang HO, Rhee DK, Pyo S. Immunostimulating effects of acidic polysaccharides extract of Panax ginseng on macrophage function. Immunopharmacol Immunotoxicol 2002;24:469-482.

17. Lim DS, Bae KG, Jung IS, Kim CH, Yun YS, Song JY. Anti-septicaemic effect of polysaccharide from Panax ginseng by macrophage activation. J Infect 2002;45:3238.

18. Choi HS, Kim KH, Sohn E, Park JD, Kim BO, Moon EY, Rhee DK, Pyo S. Red ginseng acidic polysaccharide (RGAP) in combination with IFN-gamma results in enhanced macrophage function through activation of the NF-kappaB pathway. Biosci Biotechnol Biochem 2008;72:1817-1825.

19. Friedl R, Moeslinger T, Kopp B, Spieckermann PG. Stimulation of nitric oxide synthesis by the aqueous extract of Panax ginseng root in RAW 264.7 cells. Br J Pharmacol 2001;134:1663-1670.

20. Wang H, Actor JK, Indrigo J, Olsen M, Dasgupta A. Asian and Siberian ginseng as a potential modulator of immune function: an in vitro cytokine study using mouse macrophages. Clin Chim Acta 2003;327:123-128.

21. Palucka K, Banchereau J. Dendritic cells: a link between innate and adaptive immunity. J Clin Immunol 1999;19:12-25.

22. Stockwin LH, McGonagle D, Martin IG, Blair GE. Dendritic cells: immunological sentinels with a central role in health and disease. Immunol Cell Biol 2000;78:91-102.

23. Kim MH, Byon YY, Ko EJ, Song JY, Yun YS, Shin T, Joo HG. Immunomodulatory activity of ginsan, a polysaccharide of Panax ginseng, on dendritic cells. Korean J Physiol Pharmacol 2009;13:169-173.

24. Takei M, Tachikawa E, Hasegawa H, Lee JJ. Dendritic cells maturation promoted by M1 and M4, end products of steroidal ginseng saponins metabolized in digestive 
tracts, drive a potent Th1 polarization. Biochem Pharmacol 2004;68:441-452.

25. Su W, Sun AJ, Xu DL, Zhang HQ, Yang L, Yuan LY, Jia JG, Zou YZ, Wu YL, Wang KQ et al. Inhibiting effects of total saponins of Panax ginseng on immune maturation of dendritic cells induced by oxidized-low density lipoprotein. Cell Immunol 2010;263:99-104.

26. Tung NH, Quang TH, Son JH, Koo JE, Hong HJ, Koh YS, Song GY, Kim YH. Inhibitory effect of ginsenosides from steamed ginseng-leaves and flowers on the LPSstimulated IL-12 production in bone marrow-derived dendritic cells. Arch Pharm Res 2011;34:681-685.

27. Vivier E, Nunes JA, Vely F. Natural killer cell signaling pathways. Science 2004;306:1517-1519.

28. Kenarova B, Neychev H, Hadjiivanova C, Petkov VD. Immunomodulating activity of ginsenoside $\mathrm{Rg} 1$ from Panax ginseng. Jpn J Pharmacol 1990;54:447-454.

29. Kim JY, Germolec DR, Luster MI. Panax ginseng as a potential immunomodulator: studies in mice. Immunopharmacol Immunotoxicol 1990;12:257-276.

30. See DM, Broumand N, Sahl L, Tilles JG. In vitro effects of echinacea and ginseng on natural killer and antibodydependent cell cytotoxicity in healthy subjects and chronic fatigue syndrome or acquired immunodeficiency syndrome patients. Immunopharmacology 1997;35:229235 .

31. Hansson GK, Libby P, Schonbeck U, Yan ZQ. Innate and adaptive immunity in the pathogenesis of atherosclerosis. Circ Res 2002;91:281-291.

32. Kurtz J. Memory in the innate and adaptive immune systems. Microbes Infect 2004;6:1410-1417.

33. Slifka MK, Antia R, Whitmire JK, Ahmed R. Humoral immunity due to long-lived plasma cells. Immunity 1998;8:363-372.

34. Newton SM, Jacob CO, Stocker BA. Immune response to cholera toxin epitope inserted in Salmonella flagellin. Science 1989;244:70-72.

35. Vecchiarelli A, Casadevall A. Antibody-mediated effects against Cryptococcus neoformans: evidence for interdependency and collaboration between humoral and cellular immunity. Res Immunol 1998;149:321-333.

36. Dunkelberger JR, Song WC. Complement and its role in innate and adaptive immune responses. Cell Res 2010;20:34-50.

37. Liou CJ, Huang WC, Tseng J. Long-term oral administration of ginseng extract modulates humoral immune response and spleen cell functions. Am J Chin Med 2005;33:651-661.

38. Liou CJ, Li ML, Tseng J. Intraperitoneal injection of ginseng extract enhances both immunoglobulin and cytokine production in mice. Am J Chin Med 2004;32:75-88.

39. Na HS, Lim YJ, Yun YS, Kweon MN, Lee HC. Ginsan enhances humoral antibody response to orally delivered antigen. Immune Netw 2010;10:5-14.

40. Yoo DG, Kim MC, Park MK, Park KM, Quan FS, Song JM, Wee JJ, Wang BZ, Cho YK, Compans RW et al. Protective effect of ginseng polysaccharides on influenza viral infection. PLoS One 2012;7:e33678.

41. Qu DF, Yu HJ, Liu Z, Zhang DF, Zhou QJ, Zhang HL, Du AF. Ginsenoside Rg1 enhances immune response induced by recombinant Toxoplasma gondii SAG1 antigen. Vet Parasitol 2011;179:28-34.

42. Sumiyoshi M, Sakanaka M, Kimura Y. Effects of red ginseng extract on allergic reactions to food in Balb/c mice. $\mathrm{J}$ Ethnopharmacol 2010;132:206-212.

43. Behrens G, Li M, Smith CM, Belz GT, Mintern J, Carbone FR, Heath WR. Helper T cells, dendritic cells and CTL Immunity. Immunol Cell Biol 2004;82:84-90.

44. Russell JH, Ley TJ. Lymphocyte-mediated cytotoxicity. Annu Rev Immunol 2002;20:323-370.

45. Berek L, Szabo D, Petri IB, Shoyama Y, Lin YH, Molnar J. Effects of naturally occurring glucosides, solasodine glucosides, ginsenosides and parishin derivatives on multidrug resistance of lymphoma cells and leukocyte functions. In Vivo 2001;15:151-156.

46. Hwang I, Ahn G, Park E, Ha D, Song JY, Jee Y. An acidic polysaccharide of Panax ginseng ameliorates experimental autoimmune encephalomyelitis and induces regulatory T cells. Immunol Lett 2011;138:169-178.

47. Lee EJ, Ko E, Lee J, Rho S, Ko S, Shin MK, Min BI, Hong MC, Kim SY, Bae H. Ginsenoside Rg1 enhances CD4(+) T-cell activities and modulates Th1/Th2 differentiation. Int Immunopharmacol 2004;4:235-244.

48. Seo N, Hayakawa S, Tokura Y. Mechanisms of immune privilege for tumor cells by regulatory cytokines produced by innate and acquired immune cells. Semin Cancer Biol 2002;12:291-300.

49. Alfano M, Poli G. Role of cytokines and chemokines in the regulation of innate immunity and HIV infection. Mol Immunol 2005;42:161-182.

50. Iwasaki A, Medzhitov R. Toll-like receptor control of the adaptive immune responses. Nat Immunol 2004;5:987995.

51. Medzhitov R. Toll-like receptors and innate immunity. Nat Rev Immunol 2001;1:135-145.

52. Liou CJ, Huang WC, Tseng J. Short-term oral administration of ginseng extract induces type- 1 cytokine production. Immunopharmacol Immunotoxicol 2006;28:227240.

53. Kim KH, Lee YS, Jung IS, Park SY, Chung HY, Lee IR, 
Yun YS. Acidic polysaccharide from Panax ginseng, ginsan, induces Th1 cell and macrophage cytokines and generates LAK cells in synergy with rIL-2. Planta Med 1998;64:110-115.

54. Ahn JY, Song JY, Yun YS, Jeong G, Choi IS. Protection of Staphylococcus aureus-infected septic mice by suppression of early acute inflammation and enhanced antimicrobial activity by ginsan. FEMS Immunol Med Microbiol 2006;46:187-197.

55. Park JS, Shin JA, Jung JS, Hyun JW, Van Le TK, Kim DH, Park EM, Kim HS. Anti-inflammatory mechanism of compound $\mathrm{K}$ in activated microglia and its neuroprotective effect on experimental stroke in mice. J Pharmacol Exp Ther 2012;341:59-67.

56. Kim TW, Joh EH, Kim B, Kim DH. Ginsenoside Rg5 ameliorates lung inflammation in mice by inhibiting the binding of LPS to toll-like receptor-4 on macrophages. Int Immunopharmacol 2012;12:110-116.

57. Kim HA, Kim S, Chang SH, Hwang HJ, Choi YN. Antiarthritic effect of ginsenoside Rb1 on collagen induced arthritis in mice. Int Immunopharmacol 2007;7:1286-1291.

58. Nakaya TA, Kita M, Kuriyama H, Iwakura Y, Imanishi J. Panax ginseng induces production of proinflammatory cytokines via toll-like receptor. J Interferon Cytokine Res 2004;24:93-100.

59. Ahn JY, Choi IS, Shim JY, Yun EK, Yun YS, Jeong G, Song JY. The immunomodulator ginsan induces resistance to experimental sepsis by inhibiting Toll-like receptor-mediated inflammatory signals. Eur J Immunol 2006;36:37-45.

60. Constant SL, Bottomly K. Induction of Th1 and Th2 CD4+ T cell responses: the alternative approaches. Annu Rev Immunol 1997;15:297-322.

61. Han SK, Song JY, Yun YS, Yi SY. Ginsan improved Th1 immune response inhibited by gamma radiation. Arch Pharm Res 2005;28:343-350.

62. Larsen MW, Moser C, Hoiby N, Song Z, Kharazmi A. Ginseng modulates the immune response by induction of interleukin-12 production. APMIS 2004;112:369-373.

63. Lee JH, Han Y. Ginsenoside Rg1 helps mice resist to disseminated candidiasis by Th1 type differentiation of CD4+ T cell. Int Immunopharmacol 2006;6:1424-1430.

64. Song Z, Moser C, Wu H, Faber V, Kharazmi A, Hoiby $\mathrm{N}$. Cytokine modulating effect of ginseng treatment in a mouse model of Pseudomonas aeruginosa lung infection. J Cyst Fibros 2003;2:112-119.

65. Rivera E, Ekholm Pettersson F, Inganas M, Paulie S, Gronvik KO. The Rb1 fraction of ginseng elicits a balanced Th1 and Th2 immune response. Vaccine 2005;23: 5411-5419.
66. Yang Z, Chen A, Sun H, Ye Y, Fang W. Ginsenoside Rd elicits Th1 and Th2 immune responses to ovalbumin in mice. Vaccine 2007;25:161-169.

67. Gabay C, Kushner I. Acute-phase proteins and other systemic responses to inflammation. N Engl J Med 1999;340:448-454.

68. Nagy G, Clark JM, Buzas EI, Gorman CL, Cope AP. Nitric oxide, chronic inflammation and autoimmunity. Immunol Lett 2007;111:1-5.

69. Manzo A, Bombardieri M, Humby F, Pitzalis C. Secondary and ectopic lymphoid tissue responses in rheumatoid arthritis: from inflammation to autoimmunity and tissue damage/remodeling. Immunol Rev 2010;233:267-285.

70. Kim DY, Yang WM. Panax ginseng ameliorates airway inflammation in an ovalbumin-sensitized mouse allergic asthma model. J Ethnopharmacol 2011;136:230-235.

71. Oyagi A, Ogawa K, Kakino M, Hara H. Protective effects of a gastrointestinal agent containing Korean red ginseng on gastric ulcer models in mice. BMC Complement Altern Med 2010;10:45.

72. Babayigit A, Olmez D, Karaman O, Bagriyanik HA, Yilmaz O, Kivcak B, Erbil G, Uzuner N. Ginseng ameliorates chronic histopathologic changes in a murine model of asthma. Allergy Asthma Proc 2008;29:493-498.

73. Lim YJ, Na HS, Yun YS, Choi IS, Oh JS, Rhee JH, Cho BH, Lee HC. Suppressive effects of ginsan on the development of allergic reaction in murine asthmatic model. Int Arch Allergy Immunol 2009;150:32-42.

74. Zhu J, Jiang Y, Wu L, Lu T, Xu G, Liu X. Suppression of local inflammation contributes to the neuroprotective effect of ginsenoside $\mathrm{Rb} 1$ in rats with cerebral ischemia. Neuroscience 2012;202:342-351.

75. Chang SH, Choi Y, Park JA, Jung DS, Shin J, Yang JH, Ko SY, Kim SW, Kim JK. Anti-inflammatory effects of BT-201, an n-butanol extract of Panax notoginseng, observed in vitro and in a collagen-induced arthritis model. Clin Nutr 2007;26:785-791.

76. Kim KR, Chung TY, Shin H, Son SH, Park KK, Choi JH, Chung WY. Red ginseng saponin extract attenuates murine collagen-induced arthritis by reducing pro-inflammatory responses and matrix metalloproteinase-3 expression. Biol Pharm Bull 2010;33:604-610.

77. Bae EA, Han MJ, Shin YW, Kim DH. Inhibitory effects of Korean red ginseng and its genuine constituents ginsenosides Rg3, Rf, and Rh2 in mouse passive cutaneous anaphylaxis reaction and contact dermatitis models. Biol Pharm Bull 2006;29:1862-1867.

78. Hong CE, Lyu SY. Anti-inflammatory and anti-oxidative effects of Korean red ginseng extract in human keratinocytes. Immune Netw 2011;11:42-49. 
79. Samukawa K, Izumi Y, Shiota M, Nakao T, Osada-Oka M, Miura K, Iwao H. Red ginseng inhibits scratching behavior associated with atopic dermatitis in experimental animal models. J Pharmacol Sci 2012;118:391-400.

80. Lee JH, Cho SH. Korean red ginseng extract ameliorates skin lesions in NC/Nga mice: an atopic dermatitis model. J Ethnopharmacol 2011;133:810-817.

81. Park HJ, Byeon HE, Choi KW, Rhee DK, Lee KR, Pyo $\mathrm{SN}$. Inhibitory effects of ginsenoside Rb1 on atopic dermatitis-like skin lesions in mice. J Ginseng Res 2010;34: 363-368.

82. Lee KG, Son SW. Efficacy of Korean red ginseng in the treatment of atopic dermatitis. J Ginseng Res 2011;35: 149-154.

83. Gonzalez-Lamothe R, Mitchell G, Gattuso M, Diarra MS, Malouin F, Bouarab K. Plant antimicrobial agents and their effects on plant and human pathogens. Int J Mol Sci 2009; 10:3400-3419.

84. Song ZJ, Johansen HK, Faber V, Hoiby N. Ginseng treatment enhances bacterial clearance and decreases lung pathology in athymic rats with chronic $P$. aeruginosa pneumonia. APMIS 1997;105:438-444.

85. Song Z, Johansen HK, Faber V, Moser C, Kharazmi A, Rygaard J, Hoiby N. Ginseng treatment reduces bacterial load and lung pathology in chronic Pseudomonas aeruginosa pneumonia in rats. Antimicrob Agents Chemother 1997;41:961-964.

86. Pizarro-Cerda J, Cossart P. Bacterial adhesion and entry into host cells. Cell 2006;124:715-727.

87. Lee JH, Shim JS, Chung MS, Lim ST, Kim KH. Inhibition of pathogen adhesion to host cells by polysaccharides from Panax ginseng. Biosci Biotechnol Biochem 2009;73:209-212.

88. Lee JH, Shim JS, Lee JS, Kim MK, Chung MS, Kim KH. Pectin-like acidic polysaccharide from Panax ginseng with selective antiadhesive activity against pathogenic bacteria. Carbohydr Res 2006;341:1154-1163.

89. Fukuyama N, Shibuya M, Orihara Y. Antimicrobial polyacetylenes from Panax ginseng hairy root culture. Chem Pharm Bull (Tokyo) 2012;60:377-380.

90. Lee JH, Park EK, Uhm CS, Chung MS, Kim KH. Inhibition of Helicobacter pylori adhesion to human gastric adenocarcinoma epithelial cells by acidic polysaccharides from Artemisia capillaris and Panax ginseng. Planta Med 2004;70:615-619.

91. Park S, Yeo M, Jin JH, Lee KM, Jung JY, Choue R, Cho SW, Hahm KB. Rescue of Helicobacter pylori-induced cytotoxicity by red ginseng. Dig Dis Sci 2005;50:12181227.

92. Song Z, Johansen HK, Moser C, Høiby N. Effects of Chi- nese medicinal herbs on a rat model of chronic Pseudomonas aeruginosa lung infection. APMIS 1996;104:350354.

93. Song Z, Kong KF, Wu H, Maricic N, Ramalingam B, Priestap H, Schneper L, Quirke JM, Hoiby N, Mathee K. Panax ginseng has anti-infective activity against opportunistic pathogen Pseudomonas aeruginosa by inhibiting quorum sensing, a bacterial communication process critical for establishing infection. Phytomedicine 2010;17:1040-1046.

94. Scaglione F, Cattaneo G, Alessandria M, Cogo R. Efficacy and safety of the standardised ginseng extract G115 for potentiating vaccination against the influenza syndrome and protection against the common cold. Drugs Exp Clin Res 1996;22:65-72.

95. Chan LY, Kwok HH, Chan RW, Peiris MJ, Mak NK, Wong RN, Chan MC, Yue PY. Dual functions of ginsenosides in protecting human endothelial cells against influenza H9N2-induced inflammation and apoptosis. J Ethnopharmacol 2011;137:1542-1546.

96. Peiris M, Yuen KY, Leung CW, Chan KH, Ip PL, Lai RW, Orr WK, Shortridge KF. Human infection with influenza H9N2. Lancet 1999;354:916-917.

97. Kim JY, Kim HJ, Kim HJ. Effect of oral administration of Korean red ginseng on influenza A (H1N1) virus infection. J Ginseng Res 2011;35:104-110.

98. Quan FS, Compans RW, Cho YK, Kang SM. Ginseng and Salviae herbs play a role as immune activators and modulate immune responses during influenza virus infection. Vaccine 2007;25:272-282.

99. Douek DC, Roederer M, Koup RA. Emerging concepts in the immunopathogenesis of AIDS. Annu Rev Med 2009;60:471-484.

100. Weiss RA. How does HIV cause AIDS? Science 1993; 260:1273-1279.

101. Palella FJ Jr, Delaney KM, Moorman AC, Loveless MO, Fuhrer J, Satten GA, Aschman DJ, Holmberg SD. Declining morbidity and mortality among patients with advanced human immunodeficiency virus infection. HIV Outpatient Study Investigators. N Engl J Med 1998;338:853-860.

102. Sung H, Jung YS, Cho YK. Beneficial effects of a combination of Korean red ginseng and highly active antiretroviral therapy in human immunodeficiency virus type 1-infected patients. Clin Vaccine Immunol 2009;16:11271131.

103. Geffin R, Wolf D, Muller R, Hill MD, Stellwag E, Freitag M, Sass G, Scott GB, Baur AS. Functional and structural defects in HIV type 1 nef genes derived from pediatric long-term survivors. AIDS Res Hum Retroviruses 
2000;16:1855-1868.

104. Cho YK, Jung YS, Sung H. Frequent gross deletion in the HIV type 1 nef gene in hemophiliacs treated with Korean red ginseng: inhibition of detection by highly active antiretroviral therapy. AIDS Res Hum Retroviruses 2009;25:419-424.

105. Cho YK, Lim JY, Jung YS, Oh SK, Lee HJ, Sung H. High frequency of grossly deleted nef genes in HIV-1 infected long-term slow progressors treated with Korean red ginseng. Curr HIV Res 2006;4:447-457.

106. Cho YK, Jung YS. Dosage and duration effects of Korean red ginseng intake on frequency of gross deletions in the nef gene. J Ginseng Res 2010;34:219-226.

107. Cho YK, Jung YS, Sung H, Sim MK, Kim YK. High frequency of gross deletions in 5' LTR/gag and nef genes in patients infected with CRF02_AG of HIV type 1 who survived for over 20 years: an association with Korean red ginseng. AIDS Res Hum Retroviruses 2009;25:535541.

108. Cho YK, Jung YJ, Sung HS, Joo CH. Frequent genetic defects in the HIV-1 5'LTR/gag gene in hemophiliacs treated with Korean red ginseng: decreased detection of genetic defects by highly active antiretroviral therapy. J Ginseng Res 2011;35:413-420.

109. Cho YK, Jung YS. High frequency of gross deletions in the 5' LTR and gag regions in HIV type 1-infected longterm survivors treated with Korean red ginseng. AIDS Res Hum Retroviruses 2008;24:181-193.

110. Lee MH, Lee BH, Jung JY, Cheon DS, Kim KT, Choi CS. Antiviral effect of Korean red ginseng extract and ginsenosides on murine norovirus and feline calicivirus as surrogates for human norovirus. J Ginseng Res 2011;35:429-435.

111. Bae EA, Shin JE, Park SH, Kim DH. Inhibitory effect of ginseng polysaccharides on rotavirus infection. J Microbiol Biotechnol 2004;14:202-204.

112. O'Hagan DT, Valiante NM. Recent advances in the discovery and delivery of vaccine adjuvants. Nat Rev Drug Discov 2003;2:727-735.

113. McElrath MJ. Selection of potent immunological adjuvants for vaccine construction. Semin Cancer Biol 1995;6:375-385.

114. Singh M, O'Hagan DT. Recent advances in veterinary vaccine adjuvants. Int J Parasitol 2003;33:469-478.

115. Song X, Hu S. Adjuvant activities of saponins from traditional Chinese medicinal herbs. Vaccine 2009;27:48834890.

116. Liu CX, Xiao PG. Recent advances on ginseng research in China. J Ethnopharmacol 1992;36:27-38.

117. Sun J, Hu S, Song X. Adjuvant effects of protopanaxadiol and protopanaxatriol saponins from ginseng roots on the immune responses to ovalbumin in mice. Vaccine 2007;25:1114-1120.

118. Song X, Chen J, Sakwiwatkul K, Li R, Hu S. Enhancement of immune responses to influenza vaccine (H3N2) by ginsenoside Re. Int Immunopharmacol 2010;10:351356.

119. Song X, Zang L, Hu S. Amplified immune response by ginsenoside-based nanoparticles (ginsomes). Vaccine 2009;27:2306-2311.

120. Su F, Yuan L, Zhang L, Hu S. Ginsenosides Rg1 and Re act as adjuvant via TLR4 signaling pathway. Vaccine 2012;30:4106-4112.

121. Sun J, Song X, Hu S. Ginsenoside Rg1 and aluminum hydroxide synergistically promote immune responses to ovalbumin in BALB/c mice. Clin Vaccine Immunol 2008;15:303-307. 